\title{
A iniciativa hospital amigo da criança sob a ótica dos atores sociais que a vivenciam em Teresina, Piauí 1
}

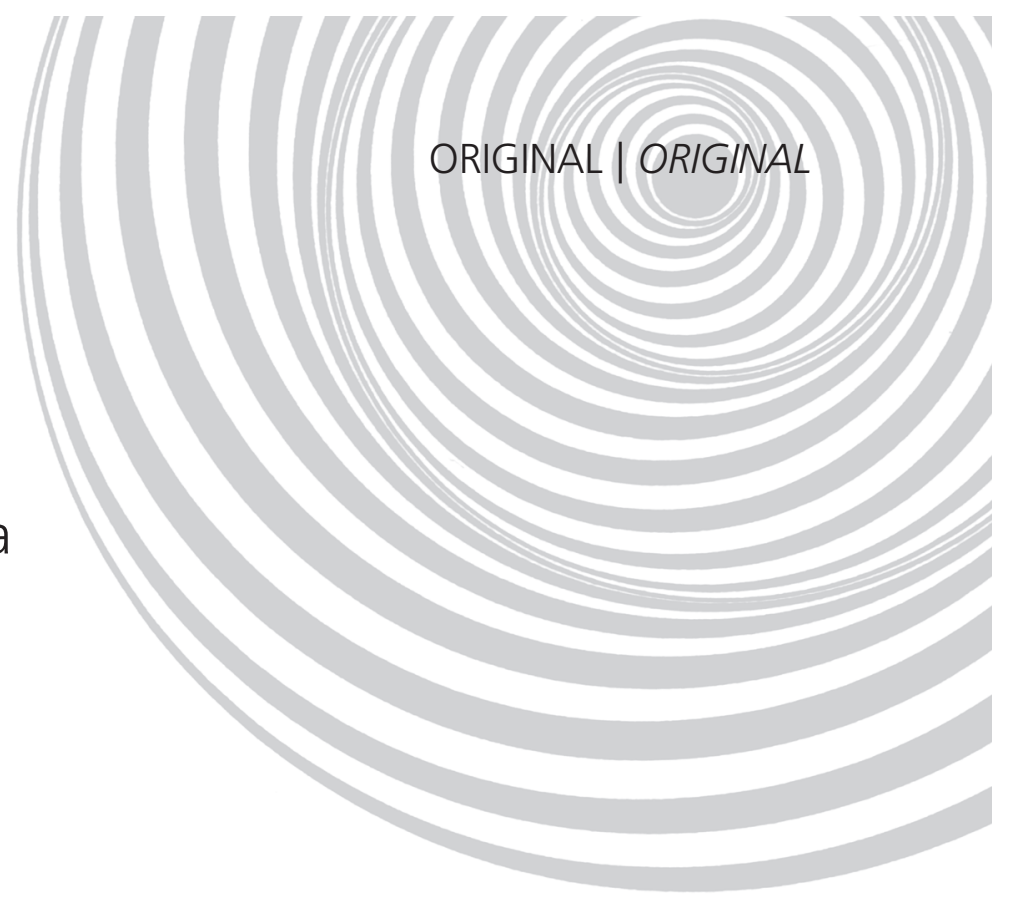

\author{
The baby-friendly hospital initiative as \\ perceived by the social actors who \\ experience it in Teresina, Piauí, Brazil
}

Carmen Viana RAMOS ${ }^{2}$

João Aprígio Guerra de ALMEIDA³

Luciana Maria Ribeiro PEREIRA²

Theonas Gomes PEREIRA ${ }^{2}$

RE S U M O

\section{Objetivo}

Analisar os reflexos da Iniciativa Hospital Amigo da Criança nos atores sociais que a vivenciam.

\section{Métodos}

Estudo qualitativo. Utilizaram-se entrevistas semiestruturadas, com auxílio de um roteiro temático, junto a vinte mulheres e dez profissionais de saúde em cinco hospitais amigos da criança em Teresina (PI). Para a análise dos dados foi utilizada a técnica de análise de conteúdo do tipo temática.

\section{Resultados}

A análise das falas levou à construção de dois eixos de discussão: um relacionado à tríade de sustentação da Iniciativa - promoção, proteção e apoio; e o outro a seu próprio modus operandi, os quais permitiram evidenciar dificuldades na implementação das normas e rotinas da Iniciativa Hospital Amigo da Criança desenvolvidas nas instituições.

\section{Conclusão}

Os resultados revelaram a necessidade de ajustes para melhorar a resolutividade do programa, com ênfase para: adoção de uma nova matriz ensino-aprendizagem pautada na educação reflexiva e na adoção dos

\footnotetext{
1 Artigo elaborado a partir da tese de C.V. RAMOS, intitulada "Reflexos da Iniciativa Hospital Amigo da Criança sobre os atores sociais que a vivenciam em Teresina-Piauí". Instituto Fernandes Figueira; 2008.

2 Faculdade de Saúde,Ciências Humanas e Tecnológicas do Piauí. R. Vitorino Orthiges Fernandes, 6123, Uruguai, 64057-100, Teresina, PI, Brasil. Correspondência para/Correspondence to: C.V. RAMOS.E-mail: <nutricarmen2@yahoo.com.br>.

3 Fundação Oswaldo Cruz, Instituto Fernandes Figueira. Rio de Janeiro, RJ, Brasil.
} 
1020 | C.V. RAMOS et al.

referenciais da pedagogia da problematização; fortalecimento das redes de apoio à mulher; investimentos na melhoria do acolhimento, tornando a relação cliente-profissional mais respeitosa e definição de um processo de monitoramento contínuo que permita a adoção de medidas corretivas sempre que se fizer necessário.

Termos de indexação: Aleitamento materno. Hospital pediátrico. Pesquisa qualitativa.

\section{A B S T R A C T}

\section{Objective}

This study analyzed the way the Baby-Friendly Hospital Initiative is perceived by the social actors involved in it.

\section{Methods}

This qualitative study administered semi-structured interviews aided by a thematic guide to twenty female patients and ten health professionals from five Baby-Friendly Hospitals in Teresina (PI), in Northeast Brazil. Thematic content analysis was used to analyze the data.

\section{Results}

Analysis of the testimonials led to two axes of discussion: one related to the foundation triad of the initiative - promotion, protection and support; and the other related to its own modus operandi, highlighting the difficulties for implementing the BFHI norms and practices carried out in these institutions.

\section{Conclusion}

The results showed that adjustments are necessary to improve the effectiveness of the program, with special emphasis to: adoption of a new teaching-learning matrix based on reflexive education; adoption of references from the pedagogy of questioning; strengthening of women's support networks; investments for improving the receptiveness, thus creating a more respectful relationship between customers and professionals; and the establishment of a continuous monitoring system that allows the implementation of corrective measures whenever necessary.

Indexing terms: Breast feeding. Hospitals, pediatric. Qualitative research.

\section{N T R O D U ÇÃ O}

A Iniciativa Hospital Amigo da Criança (IHAC), criada em 1990 pela Organização Mundial de Saúde (OMS) e Fundo das Nações Unidas para Infância (UNICEF) foi adotada pelo Brasil em 1992 e conta atualmente com 324 hospitais credenciados no País ${ }^{1}$. O programa objetiva a redução da morbimortalidade infantil com ações de promoção, proteção e apoio ao aleitamento materno implementadas em maternidades que adotam como referência os "Dez Passos" para o Sucesso do Aleitamento Materno².

Os "Dez Passos" foram elaborados com base em evidências científicas que indicam como sua implementação em maternidades aumenta os indicadores de aleitamento materno em praticamente qualquer contexto ${ }^{3}$. Contudo, o êxito do aleitamento materno depende também de outros componentes como a legislação trabalhista, a implementação do Código Internacional de Comercialização para Substitutos de Leite Materno ${ }^{4}$, a ampla informação do público e o apoio da comunidade. Conforme pode ser evidenciado nos "dez passos", a existência de uma política de treinamento de profissionais que resulte em apoio apropriado e capacitado para as mães no pré-natal, parto e no pós-parto se configura em um importante requisito para obtenção das melhorias desejadas ${ }^{2}$.

Em termos gerais, os estudos realizados com o objetivo de avaliar o impacto da IHAC nas taxas de aleitamento materno demonstram um aumento nesses índices após a implantação desta estratégia ${ }^{5,6}$. Ressalta-se que as taxas de aleitamento materno no Brasil vêm aumentando gradativamente nos últimos anos, demonstrando que as ações pró-aleitamento implementadas no País, 
dentre elas a IHAC, têm contribuído de forma positiva para essa melhoria ${ }^{7}$. Contudo, quando se trata do aleitamento materno exclusivo, a duração mediana subiu de 23 dias em 1999 para 54 dias em 2008', revelando que o Brasil permanece abaixo dos patamares recomendados pela OMS e Ministério da Saúde de aleitamento exclusivo até o sexto mês de vida.

Para Araújo \& Schmitz ${ }^{9}$, a IHAC é uma estratégia eficaz para mudar as rotinas e práticas hospitalares relacionadas ao aleitamento materno, contribuindo sobremaneira para a melhoria dos indicadores dessa prática. Entretanto, o número de HAC ainda é inexpressivo quando comparado ao total de hospitais com leitos obstétricos existentes no Brasil. Neste sentido, vale ainda salientar para as reformulações no modelo de atenção à saúde que vem sendo adotado desde o início da década de noventa no Brasil, no qual a atenção básica passa a ter um importante papel na assistência prestada à mulher e à criança, tornando necessário o investimento em ações de aleitamento dirigidas aos profissionais de saúde que trabalham nessa área. Diante disso, o Ministério da Saúde lançou em 2008 a Rede Amamenta Brasil, programa destinado à abordagem do aleitamento materno na Atenção Básica à Saúde, cujo objetivo é contribuir para aumentar os índices de aleitamento materno no País. Esta estratégia deverá se integrar às demais redes, como a IHAC e Rede Brasileira de Bancos de Leite Humano, como forma de aumentar a resolutividade das ações de apoio e estímulo ao aleitamento ${ }^{10}$.

Alguns autores, por sua vez, relacionam os baixos indicadores de aleitamento exclusivo com a adoção de um modelo assistencial pautado prioritariamente nos determinantes biológicos em detrimento dos condicionantes sociais ${ }^{11-13}$. Ou seja, condicionantes que emergem das interações realizadas no contexto do concreto vivido pela mulher e que demandam uma rede social de apoio $^{12,14,15}$. Para Souza ${ }^{15}$, a mulher conta com a rede social primária, composta pelas pessoas mais próximas e mais envolvidas durante o período de aleitamento e a rede social secundária, constituída pelos profissionais de saúde, os quais ainda demonstram dificuldades em lidar com as questões subjetivas demandadas pelo exercício do ato de aleitar.

A criação da IHAC trouxe como inovação $a$ incorporação do apoio e proteção às ações de aleitamento que antes só contemplavam aspectos relacionados à promoção ${ }^{11}$. Apesar desse reconhecimento, o autor reflete acerca das restrições do programa que não contempla a hierarquização do sistema de saúde do Brasil. Porém, a adição do significado de proteção e apoio para o aleitamento materno traz um diferencial em relação às formulações existentes anteriormente.

Diante desse cenário, podemos facilmente localizar de um lado a promoção, proteção e apoio nas ações assistenciais desenvolvidas pela Iniciativa e do outro, as demandas que emergem do cotidiano da mulher em processo de aleitamento materno. Este estudo foi delineado com o objetivo de analisar como a IHAC ecoa na clientela, nos profissionais de saúde e nas mulheres que a vivenciam em Teresina (PI). Os resultados podem vir a contribuir com subsídios para a gestão de políticas públicas de aleitamento materno em seus distintos níveis de complexidade.

\section{M É T O D O S}

Face à natureza do objeto de estudo proposto, optou-se por utilizar o referencial metodológico da pesquisa qualitativa. Este tipo de abordagem preocupa-se com os significados que os atores sociais atribuem às suas experiências do mundo social e como eles compreendem esse mundo na tentativa de interpretar os fenômenos sociais $^{16}$.

A totalidade das maternidades Amigas da Criança situadas em Teresina-Piauí, uma estadual e quatro municipais, foi incluída no estudo. Destas, somente a maternidade pertencente ao Estado é considerada de alta complexidade. As referidas maternidades dispõem de ambulatórios de puericultura, nos quais as crianças são atendidas 
por profissionais da pediatria, nutrição e Programa Saúde da Família, visto que as equipes encontram-se presentes nas próprias Unidades de Saúde alvos deste estudo. As entrevistas foram realizadas em salas reservadas situadas no espaço destinado aos ambulatórios dos hospitais pela autora responsável por esse artigo. As mulheres eram encaminhadas pelo profissional que realizava o atendimento ao final da consulta. Os dados foram coletados no período de dezembro de 2007 a fevereiro de 2008.

O critério de inclusão dos atores sociais observou a clientela assistida (mulheres que realizaram o pré-natal, parto e cujos filhos tinham idade situada entre quatro e seis meses no momento da entrevista) e os profissionais (o diretor e o responsável pelo programa de cada uma das cinco instituições alvos do estudo). A escolha das mulheres com crianças nesta faixa de idade se deu em virtude de nesse período já terem vivenciado os "dez passos" previstos na Iniciativa desenvolvida nessas instituições, além disso, já possuírem uma experiência de aleitamento materno que tornasse possível o fornecimento de informações necessárias ao tipo de entrevista realizado. Em relação aos profissionais, a escolha ocorreu por se encontrarem em posição chave para oferecer as informações que contemplassem o roteiro temático, além de estarem há pelo menos três anos na instituição, fato esse que demonstrava que já teriam passado pelo processo de avaliação ou reavaliação realizado pelo Ministério da Saúde.

O número de mulheres entrevistadas (vinte ao todo) foi definido com base no critério de saturação dos temas pesquisados pelo fato de indicar quando o conjunto de entrevistas realizadas já apresenta uma amplitude do problema estudado, bem como as suas partes de diferenças e semeIhanças ${ }^{17}$.

A coleta de dados foi conduzida com o auxílio de roteiros temáticos, tomando o cuidado para não cercear a fala dos entrevistados. No que tange às mulheres, o roteiro contemplou: por que o acompanhamento nesta maternidade; como foram: pré-natal, pré-parto, puerpério, a alta hospitalar; pontos fortes e pontos fracos; sugestões de melhoria; relação com os profissionais de saúde; a usuária frente às rotinas/normas hospitalares. No que se refere aos profissionais, o roteiro observou: desenvolvimento do programa no hospital: pré-natal, parto, puerpério, consultas de seguimento; treinamento recebido; normas e procedimentos adotados; avaliação e reavaliações; pontos fortes e pontos fracos; o profissional frente às normas; sugestões de melhorias; expectativas em relação ao programa; política pública de aleitamento.

As entrevistas foram gravadas, transcritas e posteriormente analisadas. Para a análise dos dados, foi utilizada a técnica de análise de conteúdo do tipo temática. Mais especificamente, este tipo de análise se refere à contagem de um ou vários temas ou itens de significação numa unidade de codificação previamente determinada, ou seja, consiste em descobrir os núcleos de sentido que compõem uma comunicação, cuja presença ou frequência signifique alguma coisa para o objeto analítico escolhido ${ }^{18}$.

O estudo foi aprovado pelo Comitê de Ética e Pesquisa da Faculdade de Saúde, Ciências Humanas e Tecnológicas do Piauí (NOVAFAPI), protocolo $\mathrm{N}^{\circ}$ 0153.0.043.000-7, em outubro de 2007, e todos os participantes assinaram um Termo de Consentimento Livre e Esclarecido antes da sua inclusão no estudo. Não houve recusas para participação nas entrevistas. A pesquisa foi financiada pela Fundação de Amparo à Pesquisa do Estado do Piauí (FAPEPI).

\section{RESULTADOS E DISCUSSÃO}

As mulheres eram todas residentes na cidade de Teresina, com idades entre 18 e 34 anos, sendo dez casadas, cinco solteiras e as demais viviam em união consensual. Quanto ao nível de escolaridade, 17 tinham mais de nove anos de estudo e três menos de nove anos. Em relação ao trabalho fora do lar, dez trabalhavam fora. Em relação ao tipo de aleitamento, oito estavam 
oferecendo somente leite materno; três ofertavam água e/ou chá, além do leite materno; oito incluíam outros alimentos na dieta da criança em complemento ao leite materno e uma não estava mais em aleitamento materno.

Foram entrevistados dez profissionais. Destes, quatro eram médicos, cinco eram enfermeiros e uma era nutricionista. Todos referiram ter pós-graduação e foi constatado que eles tinham no mínimo três anos de atuação nestas instituições, sendo que, à frente da Iniciativa, o menor tempo revelado por esses profissionais foi de três anos, apesar de um deles já ter mais de dez anos trabalhando com esse programa.

A análise das falas levou à construção de dois eixos de discussão voltados especificamente para a tríade que dá sustentação à IHAC - promoção, proteção e apoio - e para o seu próprio modus operandi.

\section{Tríade: promoção, proteção e apoio}

A promoção do aleitamento materno ocupa um lugar central na fala dos profissionais, que revelam nortear a sua conduta pela ênfase na informação repassada de forma verticalizada e centrada nas vantagens e nas técnicas da amamentação:

[...] as nossas palestras geralmente elas são mais atuantes no momento do parto, porque aí tem uma enfermeira na maternidade e essa enfermeira, assim que a criança nasce ela tem aquela palestra, entendeu? (E2).

[...] as ações desenvolvidas no pré-natal, o que nós temos aqui, é informar todas as gestantes sobre o aleitamento materno (E3).

O aleitamento materno, essa prática, ela já é iniciada durante as consultas do pré-natal é [...] após ou durante o período do pré-natal você trabalha a questão da importância, de posicionamento, de pega [...] (E5).
As equipes de saúde dos hospitais em estudo foram treinadas nos cursos de 18 horas sobre o Manejo e Promoção do aleitamento materno em Maternidades Amigas da Criança. É provável que a ênfase nos aspectos biológicos do aleitamento utilizados nessas capacitações tenha influenciando o discurso dos profissionais. Em 2009, o Ministério da Saúde lançou uma nova versão do Curso da IHAC intitulada "Iniciativa Hospital Amigo da Criança: revista, atualizada e ampliada para o cuidado integrado". Trata-se de um material revisado destinado à capacitação das equipes dos hospitais para implementação da política de aleitamento, através de cursos de vinte horas voltados para aplicação de conhecimentos e habilidades dos profissionais de saúde em suas práticas cotidianas tomando por base uma metodologia ensino-aprendizagem que estimula uma maior participação dos mesmos ${ }^{19}$.

Os profissionais evidenciaram que o sucesso de sua ação junto às mulheres depende da realização periódica de cursos acerca do tema. Eles acreditam que com a incorporação de novos saberes sobre aleitamento materno serão capazes de manter o interesse de seus interlocutores e de ampliar a importância de sua atuação.

A gente trabalha primeiro com a sensibilização de cada um, e essa sensibilização, ela precisa ser relembrada, ela precisa ser refeita periodicamente. A gente observa que a estimulação dos profissionais é necessária, mesmo eles tendo consciência do que é importante, isso junto aos profissionais (E4).

E quer dizer teria que ter uma manutenção dos treinamentos com mais frequência pra gente estar realmente incentivando porque os servidores acabam relaxando um pouco e esquecendo do que têm que fazer no dia a dia (E7).

As mulheres assistidas, por sua vez, reproduzem em suas falas os elementos que compõem o discurso da equipe de saúde:

[...] aí ele tinha marcado uma reunião, teve uma reunião na sala de palestras, e de 
1024 | C.V. RAMOS et al.

cara eles explicaram o que eu devia comer e o que eu não devia beber ou comer, porque deveria afetar o leite da criança. Explicaram tudo direitinho como amamentar, como limpar o seio antes da criança mamar (E8).

Nós tivemos umas aulas lá ensinando como era que a gente dava de mamar, na hora de ter o menino, tudo elas ensinavam a gente lá (E12).

Só com 15 dias, ai eu voltei, aí ele pesou, mediu e falou que estava tudo normal. Não. Só perguntaram se estava pegando o peito normal, aí disse que estava (E20).

A incorporação da proteção e do apoio ao aleitamento materno representa o mais importante diferencial da IHAC na estratégia de operar com novos valores culturais em favor do aleitamento, sobretudo no ambiente hospitalar ${ }^{11}$. Contudo, os resultados aqui obtidos evidenciam o fato das mulheres valorizarem as questões relativas à técnica da amamentação. Para Silva ${ }^{20}$, isso se deve à abordagem biologicista, que percebe o aleitamento como algo voltado apenas para a saúde e o bem estar da criança, contemplando intervenções voltadas prioritariamente para questões relacionadas ao manejo de lactação. Nesse mesmo estudo, a autora evidenciou que, muito embora os profissionais de saúde reconheçam os fatores sociais na determinação desse ato, esse reconhecimento ainda não está incorporado na sua prática, permanecendo a crença da amamentação como um fenômeno natural.

Nesse contexto, faz-se necessária a construção de ações educativas relacionadas ao aleitamento materno durante o pré-natal e no atendimento após o parto, à mulher e à família para facilitar o processo de aprendizagem e troca de experiências entre as mulheres e os profissionais de saúde. A Organização Mundial da Saúde \& Organização Panamericana de Saúde ${ }^{3}$ ressaltam que palestras sobre o valor do aleitamento materno possuem caráter duvidoso. Seriam mais eficazes se houvesse a participação das pessoas que fazem parte do entorno social da mulher, tais como o pai e a avó da criança ou amigas íntimas, e que exercem influência na sua decisão de amamentar. Acrescido a isso, o desenvolvimento de habilidades de aconselhamento e apoio entre os profissionais de saúde se revela como importante estratégia para melhorar a autoconfiança da mulher, ajudando-a no processo da amamentação ${ }^{21}$.

A importância de proteger a prática do aleitamento materno não se fez presente nas falas dos profissionais. As mulheres focaram suas preocupações na dualidade que se configura entre o trabalho e a amamentação:

Por mim ainda estava dando leite, só que tive que complementar porque voltei a trabalhar. O leite já diminuiu bastante porque eu não estou dando direto. Comecei a dar água, complementar também o leitinho (E3).

A neném já está com cinco meses e eu ainda amamento ela. Só que a doutora disse que é para me amamentar até os seis meses sem dar nada, mas já está com duas semanas que comecei a dar para ela leite porque eu trabalho a noite (E14).

A IHAC introduz mudanças nas rotinas hospitalares, com a adoção de medidas para facilitar a iniciação e o estabelecimento do aleitamento materno. Inclui ainda medidas que dependem da adoção de leis que protejam o trabalho da mulher que amamenta, assim como combate à propaganda de leites artificiais para bebês - bem como bicos, mamadeiras e chupetas - a partir da Norma Brasileira de Comercialização de Alimentos para Lactentes (NBCAL) ${ }^{22}$. Os profissionais precisam estar cientes desses aspectos para que valorizem de maneira adequada as estruturas sociais de proteção e suporte ao aleitamento materno. Nesse estudo não foi identificada nenhuma fala por parte dos profissionais que se reportassem ao cumprimento da NBCAL, ou mesmo relativa às leis de proteção à mulher que trabalha.

O apoio figurou como elemento importante para viabilizar o aleitamento materno ape- 
nas na fala das mulheres. Ele surge como uma necessidade que emerge do concreto vivido nas distintas fases do ciclo gravídico puerperal.

[...] eles faltavam também, às vezes ele (médico) atrasava, quando chegava não atendia todo mundo, mas fora isso foi bom. Eu acho que não é certo, o certo é acompanhar, conversar, saber como é que está a gestante, eu acho que é assim (E5).

Eles me auxiliaram a botar ela no peito, porque apesar de eu já saber teoricamente, mas na prática é diferente, aí elas me ensinaram (E1).

Tive dificuldade porque não tinha leite, o bebê chorava demais. Passei dois dias e meio quase três dias [...] e a pediatra ficava dando massagem no seio, massagem e massagem e saía leite bem pouquinho, mas esse ela não tomava. Aí eu pedi até pelo amor de Deus para trazer leite materno para minha filha aí que a pediatra trouxe um pouquinho de leite. Ela começou dar 8h, elas deu umas três vezes até pela manhã até na hora de ir embora. (E13).

O apoio não integrou o discurso dos profissionais. No que tange às falas das mulheres, ressaltam-se problemas sérios na assistência oferecida pelos serviços, como por exemplo, os atrasos e faltas dos profissionais relatados pelas depoentes. Este fato evidencia a necessidade do serviço em re-estruturar o atendimento realizado de forma a atender a demanda, fato esse que se mostra superior às dificuldades de implementação da IHAC. Contudo, é visível a importância que o apoio ao aleitamento materno exerce sobre as mulheres que valorizam este fato quando assim o recebem, conforme pode ser retratado na segunda fala. A literatura é extensa em trabalhos que ressaltam a influência dos fatores relacionados ao contexto social na prática, no aleitamento, demonstrando a dependência de uma rede social de apoio composta pelo serviço de saúde, família e sociedade na realização desse ato 12,14,16. Tal constatação nos obriga a refletir sobre uma nova relação profissional para este cuidar-educar, regida pela ética e responsabilidade, onde a mulher seja respeitada como um ser autônomo, e os profissionais possam se despir da sua supremacia do saber técnico, sem manter a mulher na ignorância, construindo um espaço para o diálogo com sensibilidade e reflexão ${ }^{13}$.

\section{Modus operandi da IHAC}

O primeiro aspecto que merece destaque na análise das falas dos depoentes, em relação ao modus operandi da IHAC, diz respeito à pequena adesão dos profissionais às normas e rotinas do programa:

Nos fins de semanas e feriados nós deixamos lá escrito que as enfermeiras que estão de plantão elas devem dar essa palestra, e a gente sabe que não acontecem. Enfim, resumindo, a escala na verdade ela existe, os profissionais sabem disso, mas não cumprem, principalmente no final de semana [...] (E3).

[...] tivemos um treinamento para maternidade no ano passado, foi ano passado, para os profissionais da maternidade e não apareceu nenhuma enfermeira, por incrivel que pareça. Nenhuma enfermeira e nenhum médico, entendeu (E2).

Os treinamentos têm só um problema. $O$ treinamento na verdade sobre o aleitamento, eu confesso que não participo, dou apoio e tal, vou lá e tal, mas não participo. Agora eu acho que tem que haver, tem que haver [...] (E6).

A análise da forma de operacionalização da IHAC reflete a dificuldade do modelo assistencial vigente em conseguir envolver os atores sociais a ponto de torná-los agentes sociais de transformação em favor do aleitamento materno. Este fato ecoa na fala das mulheres como importantes falhas na assistência:

Não, ninguém me falou sobre aleitamento não [...] Não tive não, porque também eu 
fiz meu pré-natal, ele (médico) faltava muito [...] (E5).

Eu não assisti, não. Quando eu saí ninguém falou nada não de palestra, não (E7).

Vale a pena ressaltar que as proposições normativas que norteiam o programa foram construídas com base em evidências científicas acerca do manejo da alimentação do recém-nascido sadio $^{3}$. Dessa forma, considera-se importante a compreensão desses aspectos pelos profissionais de saúde, fato esse que poderia contribuir para uma maior adesão desses atores sociais no desenvolvimento do programa nessas instituições. As não-conformidades verificadas entre práticas e as rotinas hospitalares observadas nas falas dos profissionais, podem estar associadas, em parte, à inexistência de um monitoramento capaz de acompanhar o dia a dia das ações da IHAC nas instituições. O processo de monitoramento é definido como uma atividade que "pressupõe um seguimento longitudinal no tempo" da implementação de uma ação, com vistas a avaliar se os planos estabelecidos estão sendo desenvolvidos, além de identificar os eventuais problemas que possam estar ocorrendo e corrigi-los no sentido de assegurar o desenvolvimento das atividades $^{23}$.

A necessidade de um monitoramento contínuo se reflete nos discursos dos profissionais ao enfatizar que os preceitos da Iniciativa são atendidos de forma mais ampla apenas nos períodos em que ocorrem as reavaliações realizadas pelo nível central.

Na véspera das reavaliações, na época que a gente fica mesmo mais voltado para essa parte de estar vendo mesmo o jeito que ele tá treinado, para que todo mundo tenha uma abrangência total no contingente do hospital todo, a gente reforça [...] (E10).

[...] eu sinto que a atuação deles em relação à obediência aos passos é mais quando a fiscalização vem, mas assim, todos tem conhecimento, todos tão treinados. Não tem um profissional de nível médio, de nível superior que não tenha recebido o treinamento [...] Mas passou essa fase pronto (E2).

"Monitorar e avaliar as intervenções e o próprio processo de implantação e implementação das mesmas é o que garante a sustentabilidade das ações"24. Para tanto, é necessário que seja conduzido sem deixar de levar em conta o ponto de vista e experiência dos diversos grupos implicados no serviço ou programa, conforme vem sendo preconizado nas metodologias participativas de avaliação de programas ${ }^{25}$. A escuta dos atores sociais - nesse caso em particular, profissionais e mulheres - acerca das dificuldades de implementação da IHAC, além das próprias sugestões de melhoria nas ações de aleitamento dentro dos hospitais se configuram como importante canal de comunicação e socialização de experiências com vistas ao alcance dos objetivos propostos. De acordo com Uchimura \& Bosi26, é imprescindível na análise da dimensão subjetiva da qualidade dos programas de saúde a experiência vivencial de atores sociais que interagem com o mesmo, sejam eles usuários, técnicos, gestores ou políticos.

Além dos problemas que decorrem da falta de um monitoramento contínuo, os profissionais ressaltam que a sustentabilidade temporal é também comprometida por aspectos intrínsecos à própria implementação da IHAC nas instituições analisadas:

[...] uma capacitação onde vai trezentos profissionais ou cinquenta de manhã cinquenta de tarde, e esse seu conhecimento teórico não é suficiente. Não é nem $20 \%$ do que nós precisamos pra gente ter serviço nos hospitais. Tem é que pegar na mão do profissional, é perguntar para ele qual é a dificuldade dele, que ele tem de colocar uma mulher para dar de mamar e para orientar, porque só essa fala [...] Chegar lá: olha, é importante o aleitamento materno porque a criança cresce, a criança estica, a criança tem desenvolvimento tal e tal. [...] você não tem profissionais capazes de resolver um problema, e não só de falar bonito, de 
falar do ponto de vista técnico, adequado, não, eu não preciso só de ouvir, não quero continuar ouvindo, ouvindo, ouvindo e não vou fazer nada, porque saber $100 \%$ de todos os profissionais aqui, de nível médio, superior, sabem, têm conhecimento (E4).

[...] ou a gente treina, qualifica as pessoas para que elas entendam o que é que estão fazendo, porque estão fazendo ou jamais conseguiremos implantar qualquer politica de saúde pública, porque de cima para baixo é praticamente impossível (E9).

A implementação inadequada do programa nessas instituições pode estar contribuindo para a não-adesão efetiva dos profissionais a essa política pública. As capacitações previstas deveriam atender o disposto nos documentos de formulação do programa, obedecendo à carga horária prevista, ao conteúdo programático proposto e ao número mínimo de pessoas para a participação nos cursos. Outro aspecto que merece consideração diz respeito à maneira como o programa ocorre nas instituições, não oferecendo possibilidades para uma discussão ampliada com os atores que dele participam acerca das normas que devem ser seguidas pelas instituições. Com isso, a tão esperada transformação dos comportamentos em favor do aleitamento materno acaba não acontecendo.

O distanciamento entre as proposições normativas do modelo assistencial da IHAC e a prática do aleitamento também se fez evidente nas falas das mulheres.

[...] é uma coisa assim que não entendo, porque tem pessoas que dizem assim: "Ah! mas o peito previne de doenças.", e o João Emílio fica doente, já gripou várias vezes, então assim, eu acho [...]. É, eu acho que vai muito assim [...], eu não sei, é o principal alimento do bebê, mas as vezes não previne tanto como [...], no meu entender (E8).

[...] ele bebe água, bebe muita água. [...] Ele toma na chuquinha. [...] Lá, eles não que-rem que a gente dê não, não querem não. Eles dizem assim: "Durante seis meses não é para dar nem água e nem outra coisa", mas a gente não vai deixar o menino sem tomar água? Hum! (E12).

Dou (mamadeira). [...] Já disseram que não serve para os dentes, mas eu acho que não (E15).

A fala das mulheres reflete a relutância em cumprir as orientações recebidas. Contudo, vale salientar que apenas uma das mulheres entrevistadas não estava mais amamentando. Esta situação talvez não fosse possível em um hospital que adotasse rotinas e procedimentos que dificultassem o aleitamento materno, tais como: separação mãe e filho, utilização de fórmulas em mamadeiras ou chuquinhas, além do fato de não promover e apoiar adequadamente esta prática. Para Labbok ${ }^{27}$, a IHAC contribuiu para o aumento constante do aleitamento materno exclusivo e total na maioria dos países, inclusive no Brasil. Entretanto, pode-se dizer que ela se encontra em sua adolescência - crescendo e mudando, e passando por revisões com vistas a se ajustar às necessidades de adaptação, expansão, integração e sustentabilidade. Rea ${ }^{7}$, refletindo sobre as mudanças alcançadas na duração do aleitamento, com a implementação de programas e ações pró-amamentação no Brasil em 25 anos, chama a atenção para a necessidade de avaliação desse processo, bem como para o impacto dessas ações no perfil de morbi-mortalidade e crescimento infantil.

Nesse estudo, em particular, as dificuldades apontadas demonstram a necessidade de redimensionar as ações estratégicas focando num contexto mais amplo que envolva o ser mulher: mãe, esposa, trabalhadora e cidadã ${ }^{28}$. Cientes disso, os profissionais de saúde que trabalham na assistência devem perceber a importância do papel a ser desempenhado no apoio à mulher que amamenta, fato esse muitas vezes valorizado por ela, apenas por sentir o bebê junto de si. Para tanto, devem responsabilizar-se em dedicar um mínimo de tempo disponível para assisti-la, explorando as necessidades que vão além do biológico $^{13}$. 
Neste sentido, faz-se necessária a capacitação profissional para atuar na assistência em amamentação numa abordagem que ultrapasse as fronteiras do biológico e possa compreender a nutriz em todas as suas dimensões do ser muIher $^{28}$. Araújo ${ }^{29}$ propõe uma nova matriz ensino-aprendizagem dirigida aos profissionais na área de aleitamento que possa conjugar os preceitos de uma educação crítico-reflexiva, educação permanente em saúde e a prática pedagógica da problematização. Este novo olhar sobre o ensino do aleitamento se volta para uma formação integralizadora, contextualizada, que considera o conhecimento prévio, tornando os profissionais corresponsáveis na construção do seu próprio conhecimento ${ }^{10}$.

Outro aspecto que mereceu destaque na fala das mulheres foi a atenção dispensada pela equipe durante todo o processo assistencial vivenciado.

Não, até têm uns aqui que são ignorantes [...]. Se a gente vai perguntar alguma coisa às vezes não responde (E5).

No pré-natal assim, só as atendentes, porque elas são muito ignorantes, são muito ignorantes. Eu acho assim, se elas querem trabalhar, elas deveriam ser mais gentis e não atender as pessoas mal, porque elas atendem muito mal, muito mal (E2).

[...] deveria ter uma reunião com essas pessoas, observar, antes de fazer essa reunião. Acho que deveriam observar como é essas pessoas atendendo, para depois fazer essa reunião e explicar: olha gente, você não pode ir tratando o próximo assim, vocês tem que se botar no lugar deles (E6).

Os depoimentos acima demonstram a insatisfação das depoentes em relação ao atendimento recebido dos profissionais de saúde. Segundo Dias \& Deslandes ${ }^{30}$, o acolhimento proporcionado através da escuta atenta e o tratamento respeitoso e educado por parte da equipe de saúde se apresentam como parte de uma solu- ção inicial para melhorar as expectativas das muIheres e que pode aumentar a confiança das usuárias nas unidades dentro de uma perspectiva mais ampla que possibilite a concepção de que um bom atendimento não deve ser mais uma rotina de saúde, e sim direito que ela pode exigir.

\section{O N C L U S Ã O}

A análise compreensiva dos discursos dos atores sociais permitiu evidenciar dificuldades por parte das equipes de saúde na implementação das normas e rotinas desenvolvidas com base nos "dez passos para o sucesso do aleitamento materno" da Iniciativa Hospital Amigo da Criança.

Neste sentido, os resultados alcançados revelam a necessidade de ajustes na forma de operacionalização da IHAC. Além disso, o estudo apontou de forma objetiva para questões a serem trabalhadas no intuito de melhorar a resolutividade do programa. Sendo assim, merecem ênfase: a adoção de uma nova matriz ensino-aprendizagem pautada na educação reflexiva e na adoção dos referenciais da pedagogia da problematização em busca de uma prática assistencial focada nas bases do aconselhamento aplicado ao assistir; o investimento em ações de fortalecimento das redes sociais de suporte à mulher que amamenta; a adoção de medidas que potencializem toda a rede de atenção básica no acompanhamento e apoio à mulher que está vivenciando esta prática; a realização de investimentos para melhorar o acolhimento nas instituições, tornando a relação cliente-profissional mais respeitosa.

Além das questões acima evidenciadas, faz-se necessária a definição de um processo de monitoramento contínuo que permita a adoção de medidas corretivas sempre que for preciso.

\section{A GRADECIMENTOS}

Aos Diretores, profissionais de saúde e mulheres assistidas nos cinco hospitais de Teresina que se dispuseram a dar as entrevistas e a Franklin Borges, professor de Inglês. 


\section{COLABORADORES}

C.V. RAMOS e J.A.G. ALMEIDA elaboraram o artigo e foram os coordenadores técnicos científicos da pesquisa. L.M.R. PEREIRA foi coordenadora administrativa da pesquisa junto à FAPEPI (Fundação de Amparo à Pesquisa do Estado do Piauí) e participou da discussão da análise e interpretação dos dados. T.G. PEREIRA participou da discussão da análise e interpretação dos dados e da revisão dos pareceres.

\section{REFERÊ N CIAS}

1. Brasil. Ministério da Saúde. Secretaria de Atenção a Saúde. Iniciativa Hospital Amigo da Criança. Brasília: MS; 2009 [acesso 2009 out 20]. Disponível em: <http://portal.saude.gov.br/portal/saude/ cidadao/area.cfm?id_area=1251>.

2. Organização Mundial de Saúde. Proteção, promoção e apoio ao aleitamento materno: o papel especial dos serviços materno-infantis. Uma declaração conjunta da OMS/UNICEF. Genebra: OMS; 1989.

3. Organização Mundial de Saúde. Evidências científicas dos dez passos para o sucesso do aleitamento materno. Brasília: OMS; 2001.

4. Organização Mundial de Saúde. Código internacional de comercialização de substitutos do leite materno. Genebra: OMS; 1981.

5. Vanuchi MTO, Monteiro CA, Rea MF, Andrade SM, Matsuo T. Iniciativa Hospital Amigo da Criança e aleitamento materno em unidade de neonatologia. Rev de Saúde Pública. 2004; 38(3):422-8. doi: 10.1590/S0034-89102004000300013.

6. Caldeira AP, Gonçalves E. Assessment of the impact of implementing the Baby-Friendly Hospital Initiative. J Pediat (Rio Janeiro). 2007; 83(2):127-32. doi: 10.1590/S0021-75572007000200006.

7. Rea MF. Reflexões sobre amamentação no Brasil: de como passamos a 10 meses de duração. Cad Saúde de Pública. 2003; 19(1 Sup):S37-S45. doi: 10.15 90/S0102-311X2003000700005.

8. Brasil. Ministério da Saúde. Secretaria de Atenção a Saúde. II Pesquisa de Prevalência do Aleitamento Materno nas Capitais e Distrito Federal. Brasília: Ministério da Saúde; 2009 [acesso 2009 set 1]. Disponível em: <http://portal.saude.gov.br/portal/ arquivos/pdf/pesquisa_pdf.pdf $>$.

9. Araújo MFM, Schmitz BAS. Doze anos de evolução da Iniciativa Hospital Amigo da Criança. Rev Panam Salud Publica. 2007; 22(2):91-9. doi: 10.1590/\$10 20-49892007000700003
10. Brasil. Ministério da Saúde. Secretaria de Atenção a Saúde. Programa rede amamenta Brasil: caderno do tutor. Brasília: MS; 2009.

11. Almeida JAG, Novak FR. Breastfeeding: a natureculture hybrid. J Pediatric. 2004; 80(5 Supl): S119 - S25. doi: 10.1590/S0021-7557200400070 0002.

12. Monteiro JCS, Gomes FA, Nakano AMS. Percepção das mulheres acerca do contato precoce e da amamentação em sala de parto. Acta Paul Enferm 2006; 19(4):427-32. doi: 10.1590/S0103-210020 06000400010.

13. Hames MLC, Carraro TE, Ramos FR, Tholl AD. A alteridade como critério para cuidar e educar nutrizes: reflexões filosóficas da prática. Rev Bras Enferm [Internet]. 2008 [acesso 2008 set 10]; 61(2): 249-53. Disponível em: <http://www.scielo.br/pdf/ reben/v61n2/a17v61n2.pdf>. doi: 16720080002 00017.

14. Ramos CV, Almeida JAG. Aleitamento materno: como é vivenciado por mulheres atendidas em uma unidade de saúde de referência na atenção materno infantil em Teresina, Piauí. Rev Bras Matern Infantil. 2003; 3(3):235-368. doi: 10.1590/\$1519-3 8292003000300010.

15. Souza MHN. A mulher que amamenta e suas relações sociais: uma perspectiva compreensiva de promoção e apoio [tese]. Rio de Janeiro: Universidade Federal do Rio de Janeiro; 2006.

16. Pope C, Mays N. Pesquisa qualitativa na atenção á saúde. $2^{a}$ ed. Porto Alegre: Artmed; 2005.

17. Minayo MCS. O Desafio do conhecimento: pesquisa qualitativa em saúde. $9^{a}$ ed. São Paulo: Hucitec; 2006.

18. Bardin L. Análise de conteúdo. $3^{\mathrm{a}}$ ed. Lisboa: Edições 70; 2004.

19. Organização Mundial de Saúde. Iniciativa hospital amigo da criança: revista, atualizada e ampliada para o cuidado integrado módulo 3 promovendo e incentivando a amamentação em um Hospital. Amigo da Criança: curso de 20 horas para equipes de maternidade. Brasília: OMS; 2009.

20. Silva IA. Construindo perspectivas sobre assistência em amamentação: um processo interacional [tese]. São Paulo: Universidade de São Paulo; 1999

21. Organização Mundial de Saúde. Guia do treinador. Aconselhamento em amamentação. Brasília: OMS; 1997.

22. Brasil. Ministério da Saúde. Portaria n 2051/GM, de 8 de novembro de 2001. Novos critérios da norma brasileira de comercialização de alimentos para lactentes e crianças de primeira infância, bicos, chupetas e mamadeiras. Diário Oficial da União, 2001; nov. 9; Seção 1; n. 215. p.44. 
23. Silver L. Aspectos metodológicos em avaliação dos serviços de saúde. In: Gallo E, et al. Planejamento criativo: novos desafios em políticas de saúde. Rio de Janeiro: Relume-Damará; 1992.

24. Nogueira-Martins MCF, Bógus CM. Considerações sobre a metodologia qualitativa como recurso para o estudo das ações de humanização em saúde. Saúde e Soc. [Internet]. 2004; [acesso 2008 ago 15]; 13(3):44-57. Disponível em: <http://www. scielo.br/pdf/sausoc/v13n3/06.pdf>. doi:10.1590/ SO 104-12902004000300006.

25. Furtado JP. Um método construtivista para a avaliação em saúde. Ciênc Saúde Coletiva [Internet]. 2001 [acesso 2008 ago 10]; 6(1):165-181. Disponível em: <http://www.scielo.br/pdf/csc/v6n1/70 34.pdf>. doi: 10.1590/S1413-81232001000100014.

26. Uchimura KY, Bosi MLM. A Polissemia da qualidade na avaliação de programas e serviços de saúde. In: Bosi MLM, Mercado FJ. Pesquisa qualitativa de serviços de saúde. Petrópolis: Vozes; 2004.

27. Labbok MH. Breastfeeding and baby-friendly hospital initiative: more important and with more evidence than ever. J Pediat (Rio de Janeiro): 2007; 83(2):99-101. doi: 10.1590/S0021-755720070002 00006.

28. Nakano MAS, Mamede, MV. A prática do aleitamento materno em um grupo de mulheres brasileiras: movimento de acomodação e resistência. Rev Latino-Am Enfermagem. 1999; 7(3):69-76. doi: 10.1590/S0104-11691999000300010.

29. Araújo, LDS. A construção de um novo olhar no ensino de aleitamento materno: uma contribuição da educação crítico-reflexiva [tese]. São Paulo: Universidade de São Paulo; 2005

30. Dias MAB, Deslandes SF. Expectativas sobre a assistência ao parto de mulheres usuárias de uma maternidade pública do Rio de Janeiro, Brasil: os desafios de uma política pública de humanização da assistência. Cad Saúde Pública [Internet] 2006 [acesso 2008 ago 10] 22(12):2647-55. Disponível em: <http://www.scielo.br/pdf/csp/v22n12/13.pdf>. doi: 10.1590/S0102-311X2006001200014.

Recebido em: 2/3/2009 Aprovado em: 5/7/2010 